\title{
Procedural skills training for medical registrars - is it needed?
}

\author{
Authors: Bavithra Vijayakumar, ${ }^{\mathrm{A}}$ Jamie Kitt, ${ }^{\mathrm{A}}$ Gareth Hynes, ${ }^{\mathrm{A}}$ Sarah Millette ${ }^{\mathrm{A}}$ and Michael Fitzpatrick ${ }^{\mathrm{A}}$
}

\section{Introduction}

The Royal College of Physicians' Acute Care Toolkit $8^{1}$ recommends that procedural training should be available for medical registrars at all hospitals, and simulation training is widely regarded as a key way of teaching such skills. ${ }^{2}$ Simulation training is now mandated for foundation and core medicine training / internal medicine training stage 1 trainees nationally, ${ }^{3}$ and is well delivered locally within our deanery. There is no such facility for general internal medicine (GIM) registrars, so we aimed to determine the interest, need, and pilot the delivery of such training in the procedures outlined by the Joint Royal Colleges of Physicians Training Board (2017). ${ }^{4}$

\section{Materials and methods}

An online survey was sent to GIM trainees within the Thames Valley Deanery in January 2019. Semi-structured interviews were conducted using convenience sampling between February and March 2019 to further explore the issues.

71 responses to the online survey were received and six semistructured interviews were conducted. Almost $70 \%$ of trainees felt current procedural training within the deanery to be inadequate. Trainees had limited exposure to procedures (Fig 1).

Ad-hoc procedural training during on calls was limited by lack of supervision and service demands, and despite half seeking additional training opportunities, confidence levels were low (Fig 2).

Key factors affecting trainee confidence included a lack of frequent exposure and medico-legal concerns.

$90 \%$ of trainees felt simulation training would improve their confidence levels and identified small group size, good facilitators, protected time and a relaxed environment as being important to running an effective simulation session.

Using these results, we trialled a simulation programme for GIM SpRs with the aims of augmenting trainee confidence and providing evidence of basic competency training. Three pilot sessions were run across two sites from September to October 2019. Sessions lasted 3.5 hours, with trainees rotating through the following four stations: abdominal paracentesis/ knee aspiration (station 1), chest drain insertion (station 2), DC cardioversion/ pacing (station 3) and central line insertion (station 4). Trainers

Authors: ${ }^{\mathrm{A} O x f o r d}$ University Hospitals NHS Foundation Trust, Oxford, UK

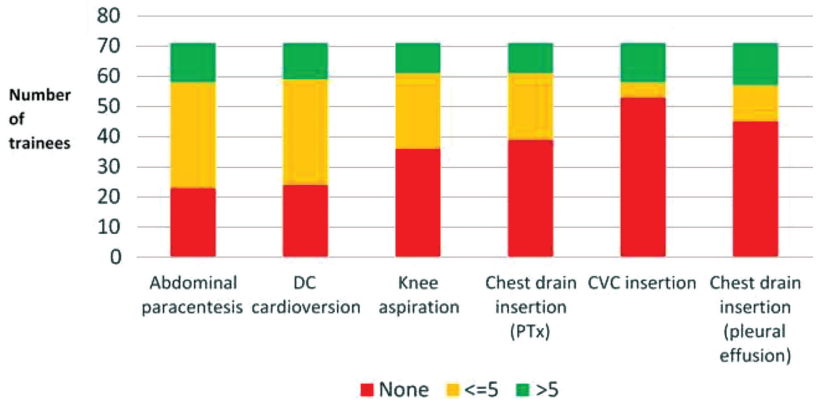

Fig 1. Number of procedures performed by trainees in the past 12 months.

were Level 3 competency senior registrars who perform the procedures regularly as part of their clinical practice.

The first pilot had 2 trainees per station and using feedback from the first pilot, the second and third pilots were expanded to 3 trainees per station. VAS score assessment of confidence was performed pre and post session by each trainee for each individual skill.

\section{Results and discussion}

32 trainees attended across both sites. Trainee grade ranged from ST3-ST7. Excellent feedback was obtained, with all trainees commenting 'the sessions were well organised, relevant to clinical practice and improved procedural skills.' All trainees rated the training as 'excellent' and a 'great initiative' with 97\% recommending incorporation into the HST curriculum. Confidence was improved by VAS scoring post training for all procedures and almost $90 \%$ felt the sessions would improve safety on GIM on calls.

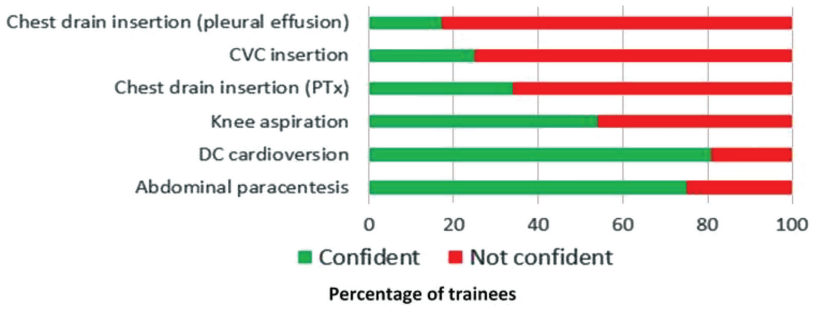

Fig 2. Trainee confidence in performing a procedure unsupervised. 


\section{Conclusion}

Simulation training is an effective way to improve trainee confidence and competence in procedural skills ${ }^{2}$ and this pilot showed such training is relevant, desired and necessitated across HST in GIM. Further work will assess its impact on maintaining trainee skillsets and its impact on patient safety.

\section{Conflicts of interest}

None declared.

\section{References}

1 The Royal College of Physicians. Acute care toolkit 8: The medical registrar on call: maximizing clinical experience, training and patient care. London: RCP, 2013. www.rcplondon.ac.uk/guidelinespolicy/acute-care-toolkit-8-medical-registrar-call [Accessed 25 October 2019].

2 Cartier V, Inan C, Zingg W et al. Simulation-based medical education training improves short and long-term competency in, and knowledge of central venous catheter insertion: $\mathrm{A}$ before and after intervention study. Eur ] Anaesthiol 2016;33:568-74.

3 Purva M, Fent G, Prakash A. Enhancing UK Core Medical Training through simulation-based education: an evidence-based approach A report from the joint JRCPTB/HEE Expert Group on Simulation in Core Medical Training. NHS, 2016. www.jrcptb.org.uk/sites/default/ files/HEE_Report_FINAL.pdf [Accessed 25 October 2019].

4 Joint Royal College of Physicians Training Board. GIM ARCP decision aid August 2017. London: JRCPTB, 2017. www.jrcptb.org. uk/sites/default/files/GIM \% 20ARCP\% 20Decision \% 20Aid \% 20\% 28August \% 202017\% 29.pdf [Accessed 25 October 2019]. 